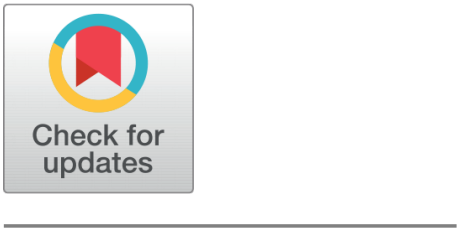

OPEN ACCESS

Received: 24.05.2021

Accepted: 05.07.2021

Published: 19.07.2021

Citation: Murali KV, Remadevi TL (2021) Photo-characterization of Organic Dye-Sensitized Tin Oxide Films . Indian Journal of Science and Technology 14(25): 2097-2105. https ://doi.org/10.17485/IJST/v14i25.818

* Corresponding author.

kvmuralikv@gmail.com

Funding: None

Competing Interests: None

Copyright: @ 2021 Murali \& Remadevi. This is an open access article distributed under the terms of the Creative Commons Attribution License, which permits unrestricted use, distribution, and reproduction in any medium, provided the original author and source are credited.

Published By Indian Society for Education and Environment (iSee)

ISSN

Print: 0974-6846

Electronic: 0974-5645

\section{Photo-characterization of Organic Dye-Sensitized Tin Oxide Films}

\author{
K V Murali ${ }^{1 *}$, T L Remadevi ${ }^{2}$ \\ 1 Department of Physics, Nehru Arts and Science College, Kanhangad, 671314, Kerala, India \\ 2 Department of Physics, Pazhassi Raja N.S.S. College, Mattannur, 670702, Kerala, India
}

\section{Abstract}

Objectives: To develop organic dye sensitized film electrodes from highly porous tin oxide $\left(\mathrm{SnO}_{2}\right)$ thin films prepared at room temperature using the SILAR technique. Methods/Analysis: $\mathrm{SnO}_{2}$ films were fabricated by the successive ionic layer adsorption and reaction (SILAR) technique at room temperature and its sensitization was done using the organic dye Rose Bengal (RB). The effect of sensitization on the as-grown and annealed film electrodes was investigated. Findings: Crystalline films with cauliflower-like morphology exhibit a large inherent adsorptive surface area and exhibit steady transmittance of $60-80 \%$ in the visible region. As-grown $\mathrm{SnO}_{2}$ films possess higher porosity and lower refractive index than that of the annealed films. $\mathrm{SnO}_{2}$ films have a resistivity in the range of $10^{-2}-10^{-3} \Omega \mathrm{cm}$. The dye adsorbed $\mathrm{SnO}_{2}$ film electrodes have much higher absorbance and cover a broad visible region compared to the bare $\mathrm{SnO}_{2}$ film electrodes. $\mathrm{RB}$ sensitization leads to an accelerated improvement in absorbed photon energy through the visible region of the spectrum extending from 2 to $3.75 \mathrm{eV}$. Novelty: Contrary to the sophisticated methods of preparation in the reported literature, highly porous crystalline $\mathrm{SnO}_{2}$ thin films were prepared at room temperature, using glacial acetic acid and hydrogen peroxide by a cost-effective simple wet chemical method. Work demonstrates that $\mathrm{SnO}_{2}$ films sensitized with $\mathrm{RB}$ act as an excellent dye-sensitized electrode, which can absorb almost half the visible spectrum (400-600 nm) of solar radiations. We believe that this is the unique report of surface modification of wet chemically prepared $\mathrm{SnO}_{2}$ electrodes by the photo-sensitizer RB.

Keywords: Photocharacterization; rose bengal; sensitization; thin films; tin oxide electrodes

\section{Introduction}

Dye-sensitized solar cells (DSC) are an inexpensive alternative to conventional p$\mathrm{n}$ junction solar cells ${ }^{(1-4)}$. Compared with the first and second-generation solar cells based on conventional semiconductor materials, the DSC exhibits relatively low efficiencies ${ }^{(3)}$. When inorganic dyes are used, the reported maximum conversion efficacy of DSCs is $12 \%^{(1)}$. This is much less than the $20-30 \%$ efficiency available from 
thin-film solar cells and Si-based solar cells ${ }^{(3)}$. This indicates that further research on photo-anode (working electrode) and related components is still necessary to carry out to improve DSCs to apply them in practice.

The structure and working of DSCs have been extensively described in detail elsewhere ${ }^{(1)}$. The important component of the DSC is the working electrode, which is a nanostructured, highly porous metal oxide film, sensitized to the visible light by an adsorbed molecular dye. The molecular dye is an essential constituent of DSC ${ }^{(1-3)}$. The photosensitive dyes are responsible for the supply of photoelectrons and the nanostructured semiconductor is transporting the charge carriers ${ }^{(1)}$.

Assembling an efficient DSC depends upon the suitable combination of metal oxide and dye ${ }^{(3)}$. Good optical transparency and electrical conductivity of the tin oxide $\left(\mathrm{SnO}_{2}\right)$ films make it a potential candidate for transparent electrodes in DSC ${ }^{(4,5)}$. $\mathrm{SnO}_{2}$ films are chemically more stable than other transparent conducting oxide films like zinc oxide and Sn-doped $\operatorname{In}_{2} \mathrm{O}_{3}$ films ${ }^{(5)}$. $\mathrm{SnO}_{2}$ semiconductor materials have good stability under irradiation in solution. But, metal oxide semiconductors could not absorb visible light for the reason that they possess wide optical band gaps. Dye-sensitized $\mathrm{SnO}_{2}$ is a promising candidate for DSCs ${ }^{(3)}$.

Inorganic dyes like metal complexes of Osmium, Iridium and Ruthenium are sensitizers exhibiting notable stability and conversion efficiency but they are very much expensive ${ }^{(1)}$. Organic dye as a photo-sensitizer is inexpensive. It has larger absorption coefficients than metal-complex photo-sensitizers and the variety in their structures allows the control of their absorption spectra ${ }^{(6)}$. The organic dye Rose Bengal (RB) in the xanthene class has an absorption peak at $559 \mathrm{~nm}$ (in ethanol) and absorbs the broad part of the visible spectrum when it stands alone. In this work, we report the use of RB as the photosensitizer to modify the surface of $\mathrm{SnO}_{2}$ film electrodes to harvest the radiations in the visible spectrum ${ }^{(6)}$.

Another very important aspect is the techniques used in metal oxide film fabrication and its sensitization. The microstructures of $\mathrm{SnO}_{2}$ films vary considerably from one deposition process to another, which in turn depends on the properties of $\mathrm{SnO}_{2}$ films significantly. Reduction in the porosity in $\mathrm{SnO}_{2}$ films may lead to the dye concentration on the surface and hence a decrease in the electron availability in DSCs ${ }^{(2)}$. The efficiency of DSCs can be enhanced by optimizing the porosity of the electrode materials used ${ }^{(1-3)}$. Among the various growth technologies, the successive ionic layer adsorption and reaction (SILAR) technique is an ideal facile technique, which offers the easy way of fabrication of nanostructured, coarse, and porous metal oxide films at room temperature ${ }^{(7)}$. This method can create mesoporous films, which provide a large internal surface area with sufficient thickness for adsorbing a large number of dye molecules and are ideally suitable for DSCs. The SILAR-films can be easily surface modified with photo-sensitizers.

This manuscript depicts the methodical fabrication and characterization of the $\mathrm{SnO}_{2}$ film electrodes together with its sensitization using the organic dye $\mathrm{RB}$. $\mathrm{SnO}_{2}$ thin films were fabricated using stannic chloride $\left(\mathrm{SnCl}_{2} \cdot 2 \mathrm{H}_{2} \mathrm{O}\right)$, glacial acetic acid, hydrogen peroxide, and distilled water by the SILAR technique. As-grown and annealed $\mathrm{SnO}_{2}$ films were utilized for sensitization and the effect of duration of sensitization was investigated. This work demonstrates that $\mathrm{SnO}_{2}$ film sensitized with RB acts as an excellent dye-sensitized electrode, which can absorb almost half the visible spectrum (400-600 nm) of solar radiations. We believe that this is the unique report of surface modification of wet chemically prepared $\mathrm{SnO}_{2}$ electrodes by the photo-sensitizer RB.

\section{Materials and Methods}

\subsection{Synthesis of $\mathrm{SnO}_{2}$ Films}

Fabrication of thin films using the SILAR process is comprehensively demonstrated in the literature ${ }^{(7)}$. The cationic precursor was prepared by mixing $2.25 \mathrm{~g}$ of $\mathrm{SnCl}_{2} \cdot 2 \mathrm{H}_{2} \mathrm{O}$ in $10 \mathrm{ml}$ glacial acetic acid (35\%) and $70 \mathrm{ml}$ of distilled water. $2 \mathrm{ml}$ of Hydrogen peroxide (25\%) in $80 \mathrm{ml}$ distilled water acts as the anionic precursor. The immersion time was optimized for $4 \mathrm{~s}$ in each of the precursor solutions kept at room temperature and an appropriate rinsing time of $8 \mathrm{~s}$ for cleaning the substrates. 250 SILAR cycles were performed for the deposition of $\mathrm{SnO}_{2}$ films. A muffle furnace was used to gradually anneal the films for 2 hours in air at $500{ }^{\circ} \mathrm{C}$.

\subsection{Preparation of the Dye Solution and Sensitization}

To sensitize the as-grown and annealed $\mathrm{SnO} 2$ films, inexpensive organic dye, $\mathrm{RB}\left(\mathrm{C}_{20} \mathrm{H}_{2} \mathrm{Cl}_{4} \mathrm{I}_{4} \mathrm{Na}_{2} \mathrm{O}_{5}\right)$ was used. $\mathrm{RB}$ is a tetraiodo substituted dye of the xanthene class of dyes. Since RB is soluble in ethanol, it was used as the solvent due to its evaporation property from the film. A certain amount of the dye was dissolved in ethanol to have a concentration of $2 \times 10^{-3} \mathrm{M}$ solution. This solution was stirred magnetically for 3 hours.

Before sensitization, films were sintered at $373 \mathrm{~K}$ for 15 minutes and were directly immersed vertically in the dye solution taken in a beaker. Sintering was carried out to avoid the adsorption of impurities from the ambient air. Dye adsorption beyond 
the optimal limit leads to the aggregation of dye on the films and hence adversely affects the DSC's performance due to the increase in resistance and the recombination loss of ejected electrons. The amount of dye loading on the films depends on the immersion time of the films in the dye solution and it plays a vital role in the DSC's efficiency ${ }^{(4)}$. Hence, three sets of as-grown and annealed $\mathrm{SnO}_{2}$ films were kept immersed in the solution for the limited duration of 12, 18, and 24 hours. Off-white films turned into pink color due to the dye adsorption. $\mathrm{SnO}_{2}$ films covered with the dye were washed in ethanol to take away the excess of dye on the surface. The dye-incorporated films were dried at room temperature for 5 days before examining their absorbance. The schematic model of the $\mathrm{SnO}_{2} / \mathrm{RB}$ film electrode and the absorbance spectrum of the $\mathrm{RB}$ dye in ethanol, which shows a peak at $559 \mathrm{~nm}$ is shown in Figure 1.
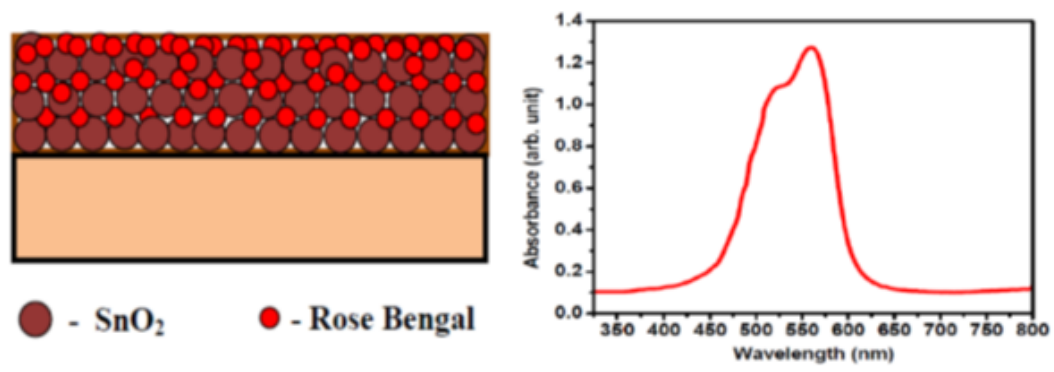

Fig 1. Schematic model of $\mathrm{SnO}_{2} / \mathrm{RB}$ film electrode (left) and the absorbance spectrum of the $\mathrm{RB}$ dye in ethanol (right)

The properties of the as-prepared, annealed and dye-sensitized $\mathrm{SnO}_{2}$ films were studied, by Bruker AXS-8 advance X-ray diffractometer, using CuKa radiation of wavelength $1.5406 \AA$. Morphological and optical studies were performed by using JEOL Model JSM6490 microscope and a Hitachi-U-3410 UV-Vis-NIR spectrophotometer respectively. Keithley source measure unit (Model SMU Keithley 2400) was used to carry out electrical studies.

\section{Results and Discussion}

The bulk density of the $\mathrm{SnO}_{2}$ is assumed as $6.99 \times 10^{3} \mathrm{~kg} / \mathrm{m}^{3}$. The thickness of the as-grown film determined using the gravimetric method is $1200 \mathrm{~nm}$. Annealed films showed no considerable change in thickness.

\subsection{Structural and Morphological Characterization}

XRD profiles and the SEM images of the highly adherent, off-white $\mathrm{SnO}_{2}$ films are shown in Figure 2(a, b) and Figure 2(c, d). The patterns for the as-grown tetragonal rutile structure $\mathrm{SnO}_{2}$ films show (110) as the dominant peak along with other peaks corresponding to reflections from (101), (211), and (301) planes (JCPDS File No. 71-0652). The films are showing excellent crystallinity compared to that of the films prepared by using sophisticated techniques reported in the literature ${ }^{(4,5)}$.
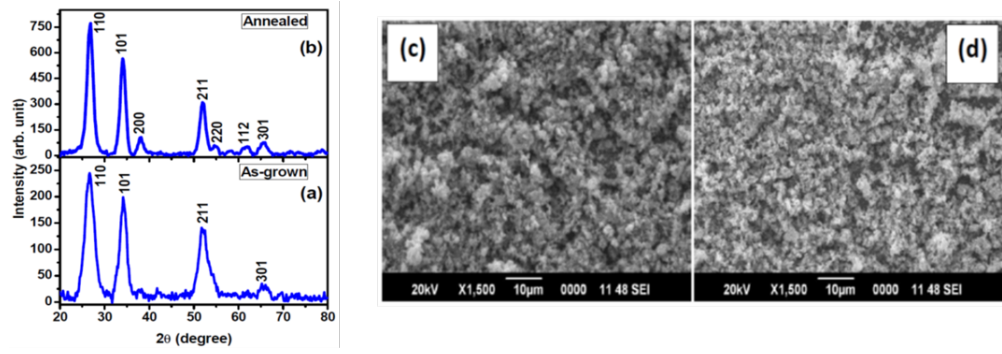

Fig 2. a \& b XRD patterns of $\mathrm{SnO}_{2}$ films, c \& d SEM images of as-prepared and annealed $\mathrm{SnO}_{2}$ films

The crystal quality of tin oxide films can be improved by eliminating the lattice disorders by gradual annealing. Annealing temperatures larger than $400^{\circ} \mathrm{C}$ is necessary to get better crystal quality ${ }^{(8)}$. Hence, $\mathrm{SnO}_{2}$ films were gradually annealed in air at $500^{\circ} \mathrm{C}$ for 2 hours. The intensity and width of the $\mathrm{SnO}_{2}$ film diffraction peaks of the annealed films shown in Figure 2 were found to increase and decrease respectively. This confirms the improvement in crystallinity and increase in the crystallite sizes of the films and/or a decrease in the strain on air annealing ${ }^{(8)}$. Lattice parameters and c/a ratio of the as-grown and annealed 
$\mathrm{SnO}_{2}$ films were determined ${ }^{(7)}$ using the refined XRD data and is depicted in Table 1 . The values obtained are close to the ideal values and are in good agreement with the reported values and the best stable structure of rutile-type $\mathrm{SnO}_{2}$ has a 'c/a' ratio equivalent to $0.674^{(7)}$.

Table 1. Lattice parameters of the as-grown and annealed $\mathrm{SnO}_{2}$ films

\begin{tabular}{llll}
\hline Sample & $\mathrm{a}(\mathrm{nm})$ & $\mathrm{c}(\mathrm{nm})$ & $\mathrm{c} / \mathrm{a}$ \\
\hline Ideal & 0.4737 & 0.3185 & 0.6724 \\
As-grown & 0.4724 & 0.3153 & 0.6674 \\
Annealed & 0.4731 & 0.3160 & 0.6678 \\
\hline
\end{tabular}

The mean crystallite sizes of $\mathrm{SnO}_{2}$ films were determined using the full-width half maximum (FWHM) of the (110) and (101) peaks using the Debye-Scherrer's equation ${ }^{(7)}$. The grain size of as-grown $\mathrm{SnO}_{2}$ films was 4 nm and that for the annealed films was $6 \mathrm{~nm}$. This indicates that annealing influences the microstructure of the films ${ }^{(8)}$.

SEM images of as-grown and annealed films show similar morphology. The films exhibit a coarse and porous surface morphology. This kind of cauliflower-like morphology is capable of affording a large inherent adsorptive surface area, which is a unique feature of films prepared using wet chemical methods ${ }^{(7)}$.

The surface of the film becomes rougher as the particle size increases. XRD studies revealed that the particle size of the annealed films has slightly increased, which implied that the surface of the film might have become rougher than the as-grown films. The porosity of the $\mathrm{SnO}_{2}$ thin film can be assessed indirectly using the refractive indices of the films ${ }^{(7,9)}$. The uniform porosity may yield to the dye distribution within the film and hence an increase in the electron availability in DSCs ${ }^{(2)}$. These films with cauliflower morphology and nanostructure grains become promising candidates in DSC applications ${ }^{(1,4)}$.

\subsection{Optical and electrical properties}

The band gap energy, $\mathrm{E}_{g}$, of the $\mathrm{SnO}_{2}$ films was evaluated ${ }^{(7)}$ by considering the allowed direct inter-band transition. In Figure 3, $(\alpha \mathrm{h} v)^{2} \mathrm{vs} h v$ plots of the films are shown. The band gap $\left(\mathrm{E}_{g}\right)$ was determined by extrapolating the linear region of $(\alpha \mathrm{h} v)^{2} \mathrm{vs}$ $h v$ plots. The optical band gap evaluated was $3.75 \mathrm{eV}$ and $3.25 \mathrm{eV}$ for the as-grown and the annealed films respectively. The inset plot in Figure 3 shows the variation of absorbance of both as-grown and annealed films. The absorbance of $\mathrm{SnO}_{2}$ films was increased on annealing and the band edge is optically red-shifted. The abrupt edge in the absorbance spectra of both as-grown and annealed films indicates the good structural quality of the film ${ }^{(10)}$.
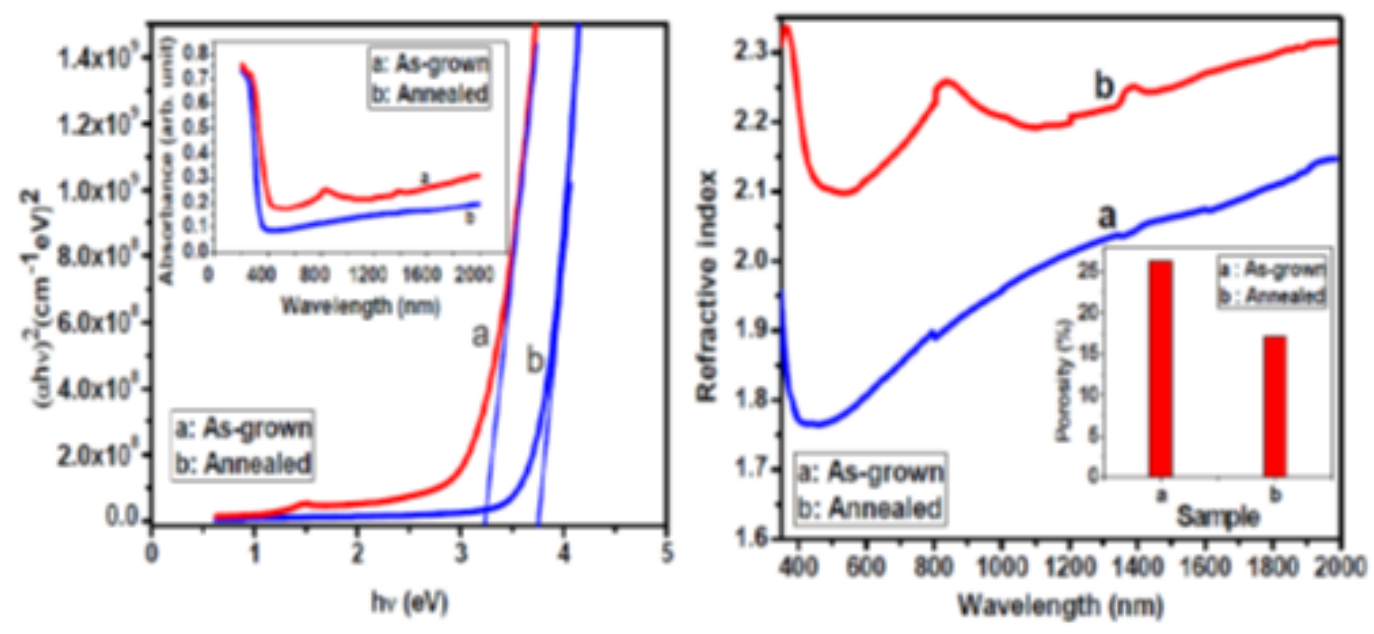

Fig 3. Plot of $(\alpha h v)^{2}$ versus $h v$ (left) and variation of refractive index with wavelength (right) of $\mathrm{SnO}_{2}$ films

The surface topography of both the substrate and the film determines the quality of the optical transmission of the film. The surface scattering due to the peculiar surface morphology of the films can reduce the transmitted intensity. Optical transmission through a rough surface is much affected by scattering of light having wavelengths near to the magnitude of the film surface features ${ }^{(9-11)}$. Due to the rough surface of the $\mathrm{SnO}_{2}$ films, it can be noticed that the as-grown films possess 
only $80 \%$ transmission in the visible region (Figure 6). The reduction in the transmittance of the annealed films to $65 \%$ in the visible region indicates that its surface roughness has increased corresponding to the particle size increase on annealing ${ }^{(9)}$. Annealed films show a decrease in transmittance throughout the Vis-NIR region. The surface topography of both the substrate and the film determines the quality of the optical transmission of the film. The reduction in the transmittance compared to the reported transmittance of $\mathrm{SnO}_{2}$ films can be attributed to the surface scattering due to the peculiar surface morphology of the films ${ }^{(9)}$. It is also evident that the optical transmission through a rough surface is much affected by the scattering of light having wavelengths near to the magnitude of the film surface features ${ }^{(10,11)}$. The light harvesting efficiency of the $\mathrm{SnO}_{2}$ working electrode will be significantly enhanced if it has light scattering capacity along with high specific surface area equivalent to that of nanoparticles ${ }^{(1)}$. Annealed films show a decrease in transmittance throughout the Vis-NIR region.

As shown in Figure 3, the refractive of the as-grown films show a lower value than that of the annealed films throughout the Vis-NIR region of the spectrum. Both the films show the lowest value of the refractive index in the visible region. The higher transmission in the visible region shown by the as-grown films may be due to the low refractive index possessed by it. Annealed films show particular values of refractive index at $900 \mathrm{~nm}$ and $1500 \mathrm{~nm}$.

The porosity of the films was computed from the refractive index of the film and refractive index $\left(\mathrm{n}_{s}\right)$ of bulk $\mathrm{SnO}_{2}\left(\mathrm{n}_{s}\right.$ 2.006) material $^{(12)}$ using the equation:

$$
P(\%)=1-\frac{n^{2}-1}{n_{s}^{2}-1}
$$

The refractive index ' $n$ ' of the films was determined using the extinction coefficient ' $k$ ' and the reflectance ' $R$ ' of the films ${ }^{(7,13)}$

As depicted inFigure 3, the as-grown $\mathrm{SnO}_{2}$ films possess higher porosity and lower refractive index than that of the annealed films. It has been reported that the refractive index of thin films decreases as the porosity increases ${ }^{(8,14)}$. This lowering of the refractive index may be due to the trapping of air (refractive index of air is unity) from the ambient atmosphere by the porous centers in the as-grown films ${ }^{(15)}$. A slight increase of particle size from $4 \mathrm{~nm}$ to $6 \mathrm{~nm}$ on annealing might have reduced the void spaces in the film and as a result, annealed films are relatively less porous and exhibit a higher refractive index.

The electrical resistivity of the as-grown films is $10^{-2}$ and that of the annealed films is $10^{-3} \Omega \mathrm{cm}$. The small grain size and the porous structure of the films greatly influence and hence reduce the carrier diffusion. This may be the reason for the moderately high electrical resistivity of the films ${ }^{(5,7)}$. The reduction in resistivity or improvement in conductivity implies that, on annealing, the slight increase in the particle size reduces the voids in the films and hence leading to the enhancement of continuity and uniformity of the films ${ }^{(10,14)} \cdot \mathrm{SnO}_{2}$ films fabricated by SILAR techniques usually show high electrical resistivity and are described elsewhere ${ }^{(7)}$. An attempt to increase the electrical conductivity to a high end will simultaneously reduce the transparency of the photo-electrode. Hence for optimal electron transport and light harvesting, the photo-electrode needs a rational design and both these properties can be simultaneously achieved by SILAR deposited films ${ }^{(4,7)}$.

\subsection{Photo-Characteristics of Sensitized $\mathrm{SnO}_{2}$ Films}

In DSCs, the dye is excited by the incident absorbing a photon and after injection of the electron into the conduction band of metal oxide it is oxidized ${ }^{(1,3,5)}$. The oxidized dye then accepts an electron from the suitable electrolyte and is regenerated ${ }^{(3,16)}$. $\mathrm{RB}$ exhibits extraordinary spectroscopic and photochemical properties together with a large absorption coefficient in the visible region. RB consists of halogens, which can act as electron acceptor groups and are known to decrease the band gap or HOMOLUMO gap of the dye $e^{(16-18)}$.

Organic dyes whose highest occupied molecular orbital (HOMO) and lowest unoccupied molecular orbital (LUMO) potential levels match the conduction-band level of the semiconductor (and the iodine redox potential) can be utilized as photo-sensitizers ${ }^{(16,18)}$. The reported value of the work function of $\mathrm{SnO}_{2}$ is $4.7 \mathrm{eV}^{(17)}$. The conduction band potential of $\mathrm{SnO}_{2}$ is approximately $0.4 \mathrm{~V}$ more positive than that of $\mathrm{TiO}_{2}{ }^{(19)}$. Photo-induced transfer of charge carrier occurs only when there is a favorable energy difference between LUMO of the RB dye and the conduction band of $\mathrm{SnO}_{2}{ }^{(16,17)}$.

Electrochemical data gives the necessary information and lets the estimation of relative positions of HOMO and LUMO levels of the materials used ${ }^{(15,16,18)}$. $\mathrm{RB}$ has an oxidation potential $\left(\mathrm{E}_{\text {ox }}\right)$ of $1.10 \mathrm{~V}$, reduction potential $\left(\mathrm{E}_{\text {red }}\right)$ of $-0.95 \mathrm{~V}, \mathrm{HOMO}$ potential level of $-5.85 \mathrm{eV}$, and LUMO potential level of $-3.82 \mathrm{eV}^{(15)}$. With this valuable information, the energy level diagram of $\mathrm{SnO}_{2} / \mathrm{RB}$ constructed is shown in Figure 4 . 


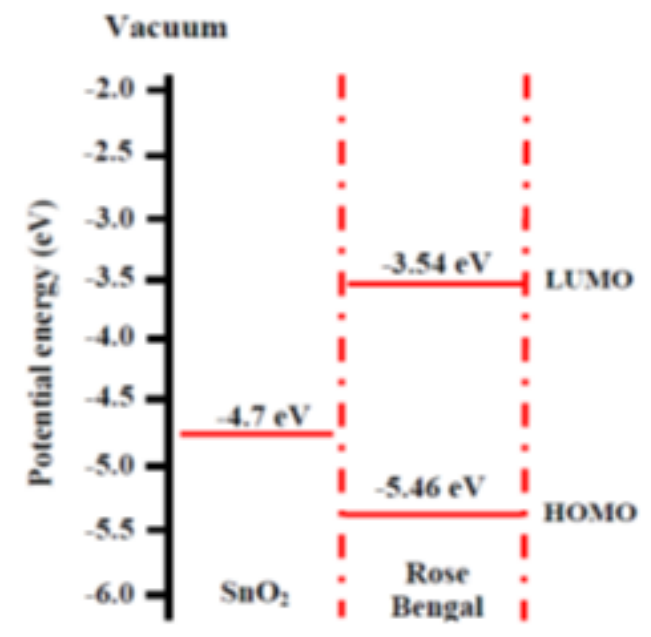

Fig 4. Schematic energy level diagram of $\mathrm{SnO}_{2} / \mathrm{RB}$

From the diagram, it is clear that the HOMO and LUMO levels of $\mathrm{RB}$ match with the conduction band level of $\mathrm{SnO}_{2}$. i.e. The excited state level of the photo-sensitizer RB is higher in energy than the conduction band edge of the $\mathrm{n}$-type semiconductor $\mathrm{SnO}_{2}$ film electrode used. Therefore, an efficient electron transfer process between the excited dye and conduction band of the semiconductor will take place ${ }^{(6,15,18)}$.
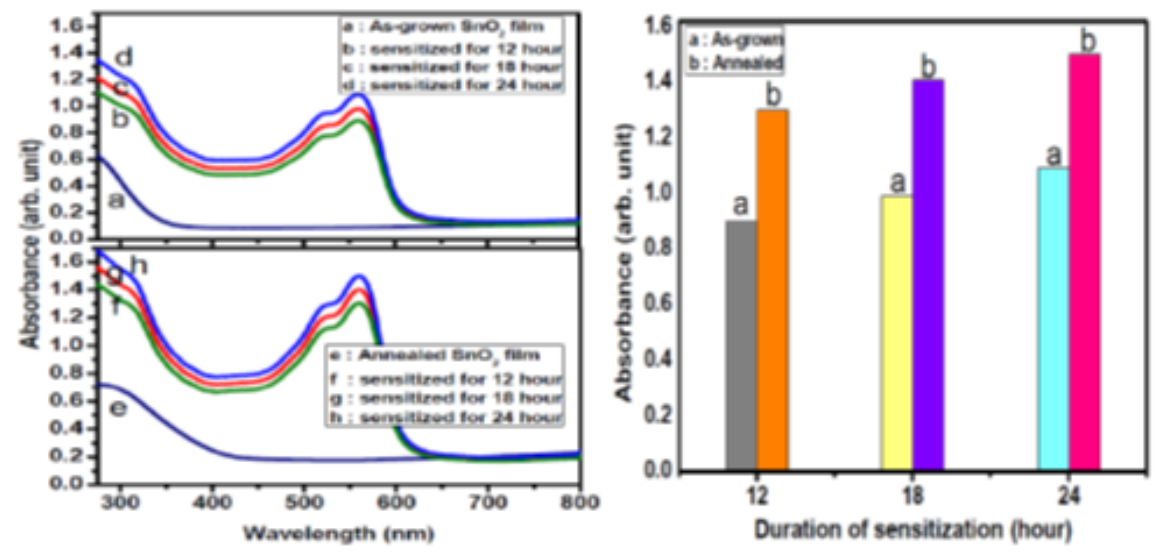

Fig 5. Absorbance spectra of bare/dye-sensitized $\mathrm{SnO}_{2}$ films (left) and the peak absorbance at 559 nm wavelength for the 12,18 and 24 hour sensitized $\mathrm{SnO}_{2}$ films (right)

Absorption spectra of the dye-sensitized as-grown and annealed $\mathrm{SnO}_{2}$ films for 12, 18, and 24-hour duration together and the bare as-grown and annealed films are shown inFigure 5. This $\mathrm{RB}$ coated $\mathrm{SnO}_{2}$ films are showing optical cut-off features in the UV and the lower part of the visible regions of the spectra $(200-600 \mathrm{~nm})$ and can be used as UV hindering panels or windows ${ }^{(20,21)}$. UV-Vis absorption spectra of solutions containing dyes detached from the sensitized film were utilized to determine the amounts of dye adsorbed by the films and are depicted in Table 2. Data give clear evidence for the sufficient amount of dye adsorption on the films. Beer-Lambert Law was used to compute the concentration of the dye detached from the sensitized films in the solution ${ }^{(22)}$.

The spectra of the dye-sensitized as-grown and annealed electrodes contain the characteristic absorption peak of RB at 559 $\mathrm{nm}$. The dye adsorbed $\mathrm{SnO}_{2}$ film electrodes show much higher absorbance and cover a broad visible region compared to the bare $\mathrm{SnO}_{2}$ film electrodes. This can be attributed to the excellent porous structure and the large specific surface area of the films. This result illustrates the adsorbance of a large number of molecules of dye in the $\mathrm{SnO}_{2}$ films.

Dye-sensitization of the film electrodes for 12, 18, and 24 hours duration has improved the absorbance but covers the same visible region respectively as shown in Figure $5^{(2,6,15)}$. The overall absorption of the sensitized films appears different 
as compared to that of the bare as-grown and annealed films. The absorption edge shifts towards the longer wavelength side and the height of the absorption peak also increases upon the duration of sensitization ${ }^{(6)}$.

Variation of the absorption peak concerning the duration of sensitization of as-grown and annealed films are shown in Figure 5. Figure 5 illustrates that more and more dye molecules are being absorbed in the film concerning the duration of immersion of the $\mathrm{SnO}_{2}$ film electrodes in the dye solution ${ }^{(6,15,18,21)}$.
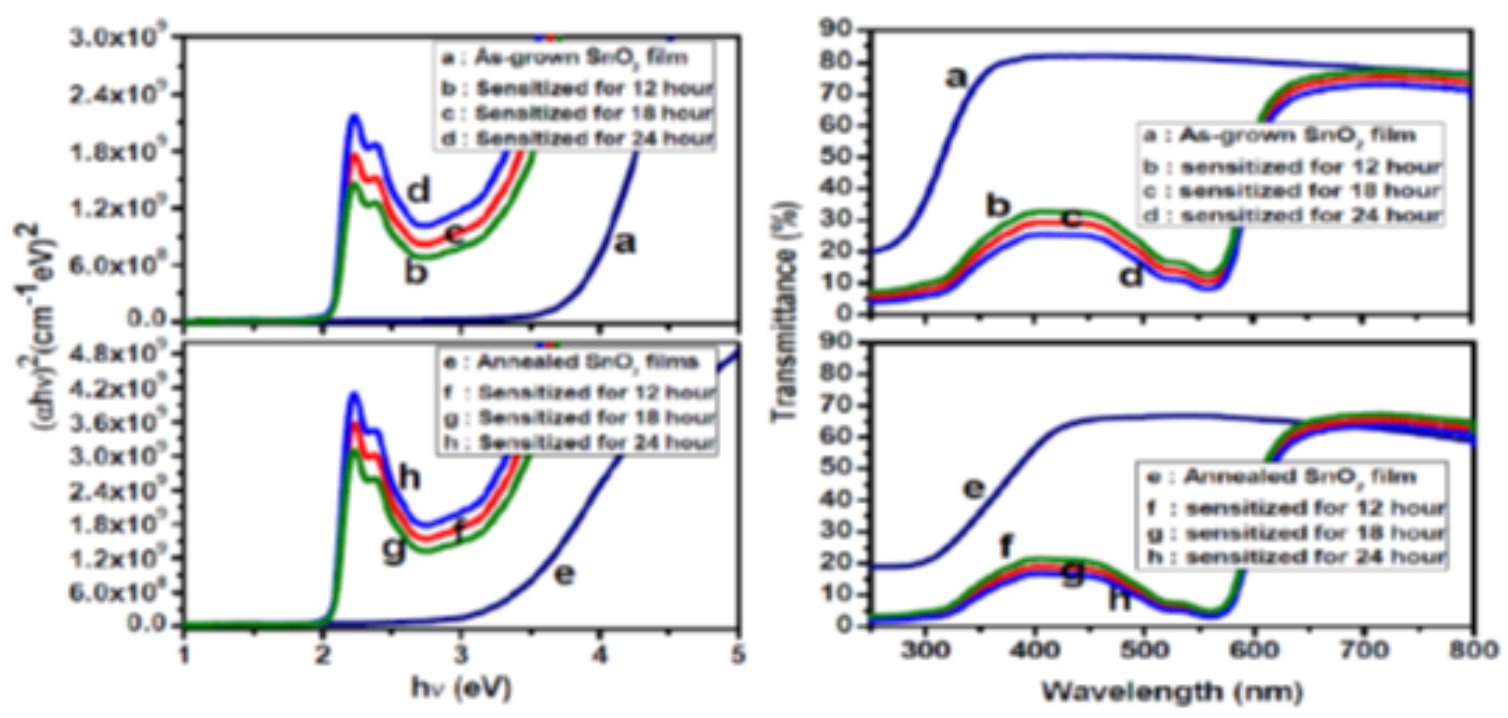

Fig 6. Plot of $(\alpha \mathrm{h} v)^{2}$ versus $\mathrm{h} v$ (left) and transmission spectra of bare/dye-sensitized (right) as-grown and annealed $\mathrm{SnO}_{2}$ electrodes

Dye-sensitized annealed $\mathrm{SnO}_{2}$ electrodes are showing higher absorbance than that of the dye-sensitized as-grown films. This can be attributed to the roughness created on the surface and the corresponding increase in specific surface area on annealing, which facilitates more dye adsorption. The transmittance in the visible region of the spectrum in Figure 6, shows that a considerable amount of dye was adsorbed by the nanocrystalline as-grown and annealed $\mathrm{SnO}_{2}$ films. The transmittance and absorbance were not affected beyond $600 \mathrm{~nm}$ in the visible region and throughout the NIR region of the light spectrum. The optical cut-off features together with the good transmission of 70-80\% beyond $600 \mathrm{~nm}$ wavelength are a favorable outcome for developing the protective windows and long-pass optical filters ${ }^{(20,21)}$.

When the films were sensitized with RB, light absorbance becomes wide and extends up to $600 \mathrm{~nm}$ in the visible region. In addition, this is caused by the decrease of band gap energy due to the surface modification of $\mathrm{SnO}_{2}$ films by $\mathrm{RB}$. The optical band gap variation due to surface modification of $\mathrm{SnO}_{2}$ films can be well understood by drawing a plot as shown in Figure 6, between incident photon energy ' $h$ ' and absorbed energy $(\alpha \mathrm{h} v)^{2}$.

The optical band gap values of $\mathrm{RB}$ sensitized $\mathrm{SnO}_{2}$ films were depicted in Table 2. It can be observed that $\mathrm{RB}$ sensitization leads to an improvement in absorbed photon energy ranging from 2 to 3.25 or $3.75 \mathrm{eV}$ respectively for the annealed and asgrown films. This is a remarkable achievement and gives clear evidence of the adsorption of RB dye on the $\mathrm{SnO}_{2}$ thin films ${ }^{(15,21)}$.

Table 2. Optical band gap of bare \& $\mathrm{RB}$ sensitized $\mathrm{SnO}_{2}$ films and adsorbed dye on the films

\begin{tabular}{|c|c|c|c|c|c|c|c|}
\hline \multirow{3}{*}{ Sample } & \multicolumn{4}{|c|}{ Optical band gap of the films $(\mathrm{eV})$} & \multicolumn{3}{|c|}{ Adsorbed dye on the films $10^{-6} \mathrm{~mol} / \mathrm{cm}^{2}$} \\
\hline & \multirow{2}{*}{ Bare films } & \multicolumn{3}{|c|}{ Sensitized for } & \multicolumn{3}{|c|}{ Sensitized for } \\
\hline & & 12 hour & 18 hour & 24 hour & 12 hour & 18 hour & 24 hour \\
\hline As-grown & 3.75 & 2.07 & 2.05 & 2.03 & 0.24 & 0.30 & 0.38 \\
\hline Annealed & 3.25 & 2.06 & 2.04 & 2.02 & 0.18 & 0.23 & 0.33 \\
\hline
\end{tabular}

Moreover, the sensitization imparts enrichment in the photoconductivity and the photo-action spectrum was broadened towards the low photon energy. Similar results have been reported regarding the change in the band gap values after dye treatment in the case of $\mathrm{N} 3$ dye-sensitized $\mathrm{TiO}_{2}$ and $\mathrm{ZnO}$ films ${ }^{(23-25)}$. All the six samples used in the study including the sensitized as-grown and annealed films established the reproducibility of the photo-response of the $\mathrm{SnO}_{2}$ films. 


\section{Conclusion}

A novel photo-anode was developed by sensitizing the SILAR $\mathrm{SnO}_{2}$ films and the effect of organic dye RB was investigated. Comprehensive characterization of the bare films and photo characteristics of the sensitized films were done.

Films with cauliflower-like morphology exhibited porous structure and a large inherent adsorptive surface area. As-grown and annealed films have a steady transmittance of $80 \%$ and $60 \%$ respectively and resistivity in the range of $10^{-2}-10^{-3} \Omega \mathrm{cm}$. As-grown $\mathrm{SnO}_{2}$ films have higher porosity and lower refractive index than that of the annealed films. The dye adsorbed $\mathrm{SnO}_{2}$ film electrodes have much higher absorbance and cover a broad visible region resulting in an improvement in light-harvesting compared to the bare $\mathrm{SnO}_{2}$ film electrodes. $\mathrm{RB}$ sensitization leads to an improvement in absorbed photon energy ranging from 2 to $3.75 \mathrm{eV}$. SnO $\mathrm{Sn}_{2}$ films sensitized with $\mathrm{RB}$ acts as an excellent dye-sensitized electrode, which can absorb the energy of almost half the visible spectrum in the range $400-600 \mathrm{~nm}$.

$\mathrm{SnO}_{2}$ film-sensitized solar cells can be constructed to investigate the performance of these photo-anodes. The potential of these sensitized films can be further explored for developing protective windows and long-pass optical filters. Long term stability of the prepared $\mathrm{SnO}_{2}$ photo-electrode was not investigated in this work. Photo-electrodes of the $\mathrm{SnO}_{2}$ films can be developed or modified further by metallic dye sensitization, doping with metallic or non-metallic materials etc.

\section{Acknowledgments}

We express our sincere gratitude to STIC, Cochin for offering technical support.

\section{References}

1) Sharma K, Sharma V, Sharma SS. Dye-Sensitized Solar Cells: Fundamentals and Current Status. Nanoscale Research Letters. 2018;13(1):381. Available from: https://dx.doi.org/10.1186/s11671-018-2760-6.

2) Souza APS, Oliveira FGS, Nunes VF, Lima FM, Almeida AFL, de Carvalho IMM, et al. High performance SnO2 pure photoelectrode in dye-sensitized solar cells achieved via electrophoretic technique. Solar Energy. 2020;211:312-323. Available from: https://dx.doi.org/10.1016/j.solener.2020.09.076.

3) Zainudin SNF, Abdullah H, Markom M. Electrochemical studies of tin oxide based-dye-sensitized solar cells (DSSC): a review. Journal of Materials Science: Materials in Electronics. 2019;30(6):5342-5356. Available from: https://dx.doi.org/10.1007/s10854-019-00929-6.

4) Arote S, Tabhane V, Jadkar S, Pathan H. Optimization of dye loading time for SnO2 based Rose Bengal dye-sensitized solar cell. Indian Journal of Physics. 2014;88(10):1067-1071. Available from: https://dx.doi.org/10.1007/s12648-014-0505-7.

5) Tao Y, Zhu B, Yang Y, Wu J, Shi X. The structural, electrical, and optical properties of SnO2 films prepared by reactive magnetron sputtering: Influence of substrate temperature and O2 flow rate. Materials Chemistry and Physics. 2020;250(123129). Available from: https://dx.doi.org/10.1016/j.matchemphys. 2020.123129.

6) Rani S, Shishodia PK, Mehra RM. Development of a dye with broadband absorbance in visible spectrum for an efficient dye-sensitized solar cell. Journal of Renewable and Sustainable Energy. 2010;2(4). Available from: https://dx.doi.org/10.1063/1.3463056.

7) Murali KV, Ragina AJ, Preetha KC, Deepa K, Remadevi TL. Wet chemical synthesis of quantum confined nanostructured tin oxide thin films by successive ionic layer adsorption and reaction technique. Materials Research Bulletin. 2013;48(9):3009-3016. Available from: https://dx.doi.org/10.1016/ j.materresbull.2013.04.059.

8) Yu KN, Xiong Y, Liu Y, Xiong C. Microstructural change of nano-SnO2grain assemblages with the annealing temperature. Physical Review B. 1997;55(4):2666-2671. Available from: https://dx.doi.org/10.1103/physrevb.55.2666.

9) Xiao X, Liu L, Ma J, Ren Y, Cheng X, Zhu Y, et al. Ordered Mesoporous Tin Oxide Semiconductors with Large Pores and Crystallized Walls for High-Performance Gas Sensing. ACS Applied Materials \& Interfaces. 2018;10(2):1871-1880. Available from: https://dx.doi.org/10.1021/acsami.7b18830. doi:10.1021/acsami.7b18830.

10) Asl HZ, Rozati SM. High-quality spray-deposited fluorine-doped tin oxide: effect of film thickness on structural, morphological, electrical, and optical properties. Applied Physics A. 2019;125(10). Available from: https://dx.doi.org/10.1007/s00339-019-2943-8.

11) Navidpour AH, Fakhrzad M, Tahari M, Abbasi S. Novel photocatalytic coatings based on tin oxide semiconductor. Surface Engineering. 2019;35(3):216226. Available from: https://dx.doi.org/10.1080/02670844.2018.1477559.

12) Yoldas BE, Partlow DP. Formation of broad band antireflective coatings on fused silica for high power laser applications. Thin Solid Films. 1985;129(12):1-14. Available from: https://dx.doi.org/10.1016/0040-6090(85)90089-6.

13) Vinodkumar R, Lethy KJ, Arunkumar PR, Krishnan RR, Pillai NV, Pillai VPM, et al. Effect of cadmium oxide incorporation on the microstructural and optical properties of pulsed laser deposited nanostructured zinc oxide thin films. Materials Chemistry and Physics. 2010;121(3):406-413. Available from: https://dx.doi.org/10.1016/j.matchemphys.2010.01.004.

14) Nisticò R, Scalarone D, Magnacca G. Sol-gel chemistry, templating and spin-coating deposition: A combined approach to control in a simple way the porosity of inorganic thin films/coatings. Microporous and Mesoporous Materials. 2017;248:18-29. Available from: https://dx.doi.org/10.1016/j. micromeso.2017.04.017.

15) Bayraktutan T. Investigation of photophysical and binding properties of Rose Bengal dye on graphene oxide and polyethyleneimine-functionalized graphene oxide nanocomposites. Chemical Papers. 2020;74(9):3017-3024. Available from: https://dx.doi.org/10.1007/s11696-020-01130-4.

16) Qin P, Yang X, Chen R, Sun L, Marinado T, Edvinsson T, et al. Influence of $\pi$-Conjugation Units in Organic Dyes for Dye-Sensitized Solar Cells. The Journal of Physical Chemistry C. 2007;111(4):1853-1860. Available from: https://dx.doi.org/10.1021/jp065550j.

17) Minami T. Toshihiro Miyata; Takashi Yamamoto Work function of transparent conducting multicomponent oxide thin films prepared by magnetron sputtering. Surface and Coatings Technology. 1996;108:592-593.

18) Sayyed SAAR, Beedri NI, Kadam VS, Pathan HM. Rose bengal-sensitized nanocrystalline ceria photoanode for dye-sensitized solar cell application. Bulletin of Materials Science. 2016;39(6):1381-1387. Available from: https://dx.doi.org/10.1007/s12034-016-1279-7. 
19) Nozik AJ, Memming R. Physical Chemistry of Semiconductor-Liquid Interfaces. The Journal of Physical Chemistry. 1996;100(31):13061-13078. Available from: https://dx.doi.org/10.1021/jp953720e.

20) El-Bashir SM, Yahia IS, Binhussain MA, Alsalhi MS. Designing of PVA/Rose Bengal long-pass optical window applications. Results in Physics. 2017;(7):1238-1244. Available from: https://doi.org/10.1016/j.rinp.2017.03.033.

21) El-Bashir SM, Yahia IS, Binhussain MA, AlSalhi MS. Design of Rose Bengal/FTO optical thin film system as a novel nonlinear media for infrared blocking windows. Results in Physics. 2017;7:1852-1858. Available from: https://dx.doi.org/10.1016/j.rinp.2017.05.027.

22) Rui Y, Xiong H, Su B, Wang H, Zhang Q, Xu J, et al. Liquid-liquid interface assisted synthesis of SnO 2 nanorods with tunable length for enhanced performance in dye-sensitized solar cells. Electrochimica Acta. 2017;227:49-60. Available from: https://dx.doi.org/10.1016/j.electacta.2017.01.004.

23) Sharma K, Sharma V, Sharma SS. Dye-Sensitized Solar Cells: Fundamentals and Current Status. Nanoscale Research Letters. 2018;13(1). Available from: https://dx.doi.org/10.1186/s11671-018-2760-6.

24) Kite SV, Sathe DJ, Patil SS, Bhosale PN, Garadkar KM. Nanostructured TiO2 thin films by chemical bath deposition method for high photoelectrochemical performance. Materials Research Express. 2018;6(2). Available from: https://dx.doi.org/10.1088/2053-1591/aaed81.

25) Rahman MU, Xie F, Li Y, Wei M. ZnO nanosheets encapsulating graphene quantum dots with enhanced performance for dye-sensitized solar cell. Journal of Electroanalytical Chemistry. 2019;840:160-164. Available from: https://dx.doi.org/10.1016/j.jelechem.2019.03.074. 